\title{
Initial surveillance of 2009 influenza A(H1N1) pandemic in the European Union and European Economic Area, April - September 2009
}

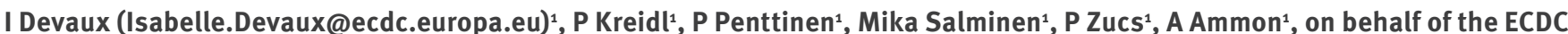
influenza surveillance group ${ }^{2}$, and the national coordinators for influenza surveillance ${ }^{3}$

1. European Centre for Disease Prevention and Control (ECDC) Stockholm, Sweden

2. The members of this group are listed at the end of this article

3. The members of the group are listed at the end of the article

Citation style for this article:

Devaux I, Kreidl P, Penttinen P, Salminen M, Zucs P, Ammon A, on behalf of the ECDC influenza surveillance group, and the national coordinators for influenza surveillance. Initial surveillance of 2009 influenza A(H1N1) pandemic in the European Union and European Economic Area, April - September 2009. Euro Surveill. 2010;15(49):pii=19740. Available online: http://www.eurosurveillance.org/ViewArticle. aspx?Articleld=19740

Article published on 9 December 2010

European Union (EU) and European Economic Area (EEA) countries reported surveillance data on 2009 pandemic influenza $\mathrm{A}\left(\mathrm{H}_{1} \mathrm{~N}_{1}\right)$ cases to the European Centre for Disease Prevention and Control (ECDC) through the Early Warning and Response System (EWRS) during the early phase of the 2009 pandemic. We describe the main epidemiological findings and their implications in respect to the second wave of the 2009 influenza pandemic. Two reporting systems were in place (aggregate and case-based) from June to September 2009 to monitor the evolution of the pandemic. The notification rate was assessed through aggregate reports. Individual data were analysed retrospectively to describe the population affected. The reporting peak of the first wave of the 2009 pandemic influenza was reached in the first week of August. Transmission was travel-related in the early stage and community transmission within EU/EEA countries was reported from June 2009. Seventy eight per cent of affected individuals were less than 30 years old. The proportions of cases with complications and underlying conditions were $3 \%$ and $7 \%$, respectively. The most frequent underlying medical conditions were chronic lung (37\%) and cardio-vascular diseases (15\%). Complication and hospitalisation were both associated with underlying conditions regardless of age. The information from the first wave of the pandemic produced a basis to determine risk groups and vaccination strategies before the start of the winter wave. Public health recommendations should be guided by early capture of profiles of affected populations through monitoring of infectious diseases.

\section{Introduction}

When the 2009 influenza $A\left(\mathrm{H}_{1} \mathrm{~N}_{1}\right)$ pandemic started in April 2009 and first cases appeared in Europe, aggregated (number of cases) and case-based (patient-based records) reporting systems were rapidly implemented by the European Centre for Disease Prevention and Control (ECDC), the European Union
(EU) and the European Economic Area (EEA) countries to fulfil the reporting requirements of the World Health Organization (WHO) and the EU [1]. The Early Warning and Response System (EWRS) was used to confidentially report aggregated and case-based data [2]. The EWRS was primarily designed as a communication platform and not as surveillance application. However, one of the main advantages of the system at the beginning of the pandemic was that it relies more on a human driven approach to reporting and this allowed timely (daily) reporting of aggregated data by the EWRS focal points in the EU/EEA countries to ECDC. The European data was then rapidly published in the ECDC's daily situation reports [3] to guide and support the response of the countries and the European Commission. Laboratory-confirmed cases of pandemic influenza were reported according to the EU case definition [4] which includes laboratory confirmation by $P C R$, antigen detection and a four-fold rise in influenza specific antibodies. A preliminary communication in this journal in June 2009, and the 2009 pandemic influenza $A\left(\mathrm{H}_{1} \mathrm{~N}_{1}\right)$ individual case reports from 2 June to 10 August $2009[5,6]$, showed that community transmission had developed in several of the EU/EEA countries since the beginning of the epidemic. A large proportion ( $77 \%$ ) of cases was reported in children and young adults less than 30 years of age. The frequency of reported symptoms was $89 \%$ for respiratory and $14 \%$ for gastro-intestinal symptoms and for $10 \%$ of pandemic influenza cases at least one underlying medical condition was reported. A number of reports from individual countries show similar data [7-15].

The objective of this article is to describe the main characteristics and risk factors of pandemic influenza cases reported by EU/EEA countries during the first pandemic wave from April to September 2009. 


\section{Methods}

The investigators extracted two datasets from the EWRS to provide numbers and characteristics of the populations infected by the pandemic influenza virus. Aggregated numbers of 2009 pandemic influenza $A\left(\mathrm{H}_{1} \mathrm{~N}_{1}\right)$ virus infections were reported by 30 EU/EEA countries by notification date from 27 April to 22 September 2009. Characteristics of cases were described on a weekly basis using case-based data reported from 5 May to 22 September 2009 (Figure 1).

Adoption of a mitigation strategy was defined as the point when a country was no longer recommending laboratory tests for all suspected cases and therefore not all pandemic influenza cases were reported to national public health authorities.

\section{Aggregated data}

Weekly notification rates were calculated by dividing the weekly aggregated number of cases reported by EU/EEA countries by their respective population extracted from the Eurostat website in August 2009 [16]. The weekly denominator only included the population of countries for as long as they reported cases to ECDC.

\section{Individual, case-based data}

The set of variables reported in the case-based system were compiled using the WHO guidance for surveillance of human infection with the 2009 pandemic influenza $\mathrm{A}\left(\mathrm{H}_{1} \mathrm{~N}_{1}\right)$ virus [17]. The variables for the characterisation of the cases were: age, sex, travel-association, vital status (alive or dead), dates (notification, onset of symptoms, treatment started and death), clinical presentation, underlying conditions, complications, antiviral treatment and prophylaxis, seasonal influenza vaccination status, and hospitalisation. Trends over time were analysed by calendar weeks (week starting on Monday).

For cases reported from 5 May to 22 September 2009, the proportion of hospitalised cases was calculated using a weekly median (by country with an interquartile range (IQR) and the 95th percentile), the distribution of travel and non travel-associated cases was described by week of onset over 22 weeks and geographic area visited, age-specific notification rates were calculated over the 20 weeks reporting period.

Completeness of reporting was calculated for sex, travel-association, antiviral treatment and prophylaxis, seasonal influenza vaccination and complication. If no data was missing, completeness equalled $100 \%$. It was not possible to calculate completeness of reporting for underlying condition as there was no option for 'none' or 'unknown' underlying condition (see list below).

Age distributions were compared between groups of persons for the variables, sex, travel-association, antiviral treatment or prophylaxis, vaccination status, underlying conditions and complications, by using two-sample Wilcoxon rank-sum (Mann-Whitney) tests.

Underlying conditions were reported according to the following pre-defined categories: cancer, diabetes mellitus, human immunodeficiency virus (HIV) infection and other immune deficiencies, heart disease, seizure disorder, lung disease, pregnancy and malnutrition. Underlying conditions could also be reported

\section{FIGURE 1}

Data for analyses of 2009 pandemic influenza A(H1N1) cases reported through the Early Warning and Response System to the European Centre for Disease Prevention and Control by European Union and European Economic Area countries, 27 April - 22 September 2009

Overall analyses

Aggregated data

Case-based data

\begin{tabular}{|c|c|}
\hline$n=51,768$ & $n=11,037^{\text {a }}$ \\
27 April - 22 September 2009 & 5 May - 22 September 2009 \\
\hline
\end{tabular}

Trend over time

\begin{tabular}{|c|c|}
\hline By date of notification & By date of onset \\
$n=51,575$ & $n=8.197$ \\
27 April - 20 September 2009 & 17 April - 20 September 2009 \\
\hline
\end{tabular}

Frequency of symptoms and underlying condition ${ }^{b}$

$n=5,205$

5 May - 22 September 2009

Risk factor analysis (hospitalisation and complication) ${ }^{c}$

$n=3,381$

5 May - 22 September 2009

${ }^{a}$ No data submitted by Greece and Liechtenstein.

${ }^{b}$ Cases for 26 countries, cases excluded from United Kingdom (inclusion of the first 301 cases only), Belgium and Slovenia (all cases excluded).

' Cases for 18 countries, cases excluded from Austria, Bulgaria, France, Latvia, Poland, Portugal, Romania. 
in a free-text field. When conditions reported in the free-text fields matched one of the pre-defined categories mentioned above, they were re-classified into this category.

Associations between outcomes of pandemic influenza, hospitalisation or complications, and the variables sex age, fever, respiratory/gastro-intestinal symptoms, antiviral treatment or prophylaxis, seasonal influenza vaccination status, underlying conditions, were analysed by unadjusted and adjusted (for other variables) logistic regression models using STATA software. Interactions between variables were tested by using the likelihood ratio test to assess the significance of each variable in the model.

\section{Datasets for specific analyses}

Figure 1 shows how subsets of data are analysed. Analyses related to the epidemiological characteristics of cases reported with pandemic influenza were performed on the full dataset $(n=11,037)$ for most of the variables. Frequency of symptoms and underlying conditions were analysed on a subset of data $(n=5,205)$ including all cases for countries other than the United Kingdom (UK) (inclusion of the first 301 cases only), Belgium and Slovenia (all cases excluded). Seven countries (Austria, Bulgaria, France, Latvia,

\section{TABLE 1}

Number of cases, notification rate, and hospitalisation rate of 2009 pandemic influenza A(H1N1) cases in European Union (EU) and European Economic Area (EEA) countries, 27 April - 22 September 2009

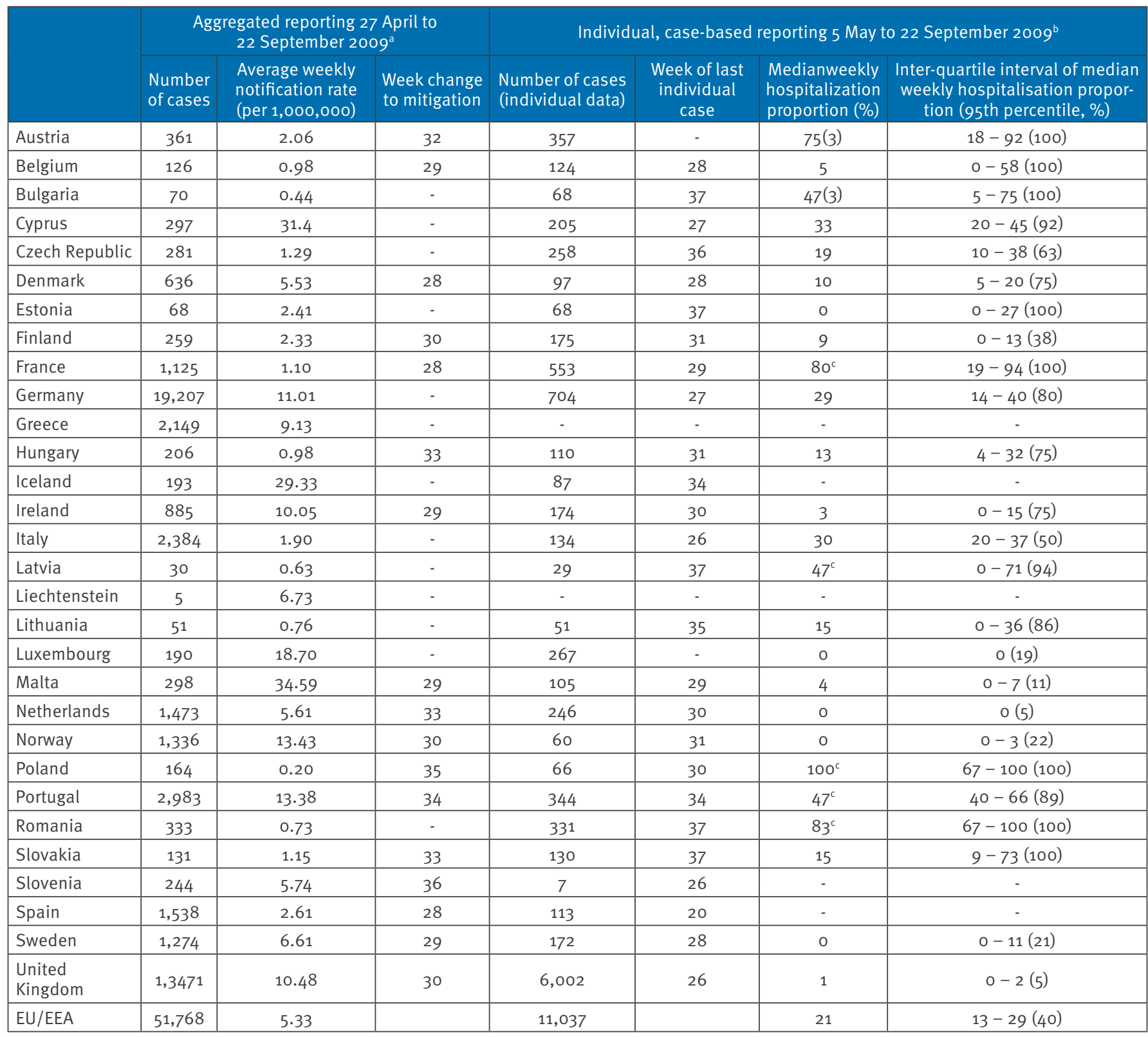

a Cases were reported by date of notification from 27 April to 22 September 2009.

${ }^{b}$ Cases were reported by date of notification from 5 May to 22 September and by date of onset from 19 April to 20 September 2009.

c Countries with high hospitalisation rate. 
Poland, Portugal, Romania) where hospitalisation was performed mainly for isolation purposes, leading to an over-representation of mild cases among hospitalised cases, were not included in risk factor analyses $(n=1,748)$.

\section{Results}

Aggregated data - weekly notification rates In total, 51,768 confirmed cases of pandemic influenza were reported as aggregated case reports by all EU/ EEA countries. The weekly notification rate was calculated for the 51,575 cases reported from 27 April to 20 September 2009 (Figure 1). It increased from week 18 to week 27 (end of June) where it peaked with eight cases per million population. A second peak in the weekly notification rate was observed in week 32 , in early August, with 13.6 cases per million population, and was followed by a decrease from week 33 , when countries progressively adopted mitigation strategies (Table 1, Figure 2).

The population used as a denominator for the weekly notification rate decreased after week 29, when countries stopped reporting pandemic influenza cases to ECDC.

The average weekly notification rate over the period described above was greater than 10 per million population in Cyprus, Germany, Iceland, Luxembourg, Malta, Norway, Portugal and the UK.

\section{Case-based data}

A cumulative number of 11,037 cases of pandemic influenza were reported as individual reports by 28 EU/EEA countries (no data submitted by Greece and Liechtenstein) from 5 May to 22 September 2009 (Table 1).The number of cases reported by the UK accounts for more than half (54\%) of the individual case reports.

\section{FIGURE 2}

2009 pandemic influenza $\mathrm{A}(\mathrm{H} 1 \mathrm{~N} 1)$ notification rate (per million population, $\mathrm{n}=51,575)$ and population of reporting European Union and European Economic Area countries by week of report, 27 April (week 18) - 20 September (week 38) 2009

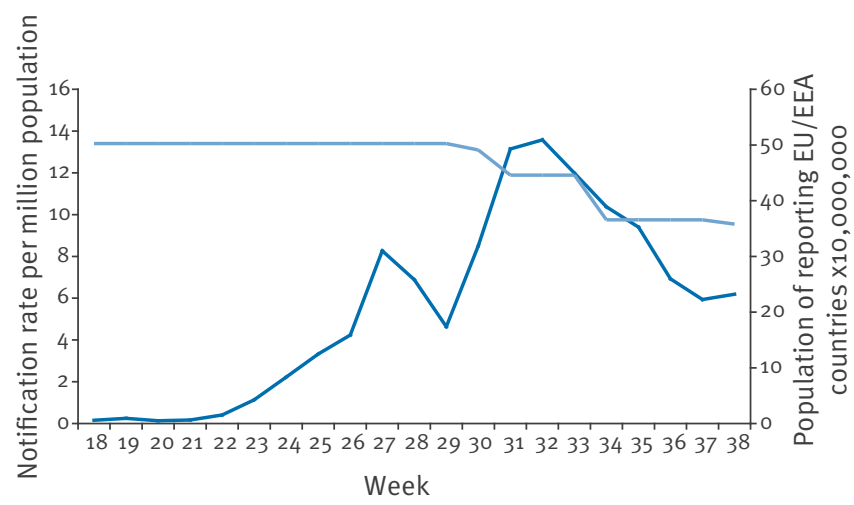

— Weekly notification rate (aggregate reporting) — Denominator (population)

EEA: European Economic Area; EU: European Union
Germany and France reported more than 500 cases; Spain stopped reporting individual cases before the end of June 2009. Data by week of onset were available for $8,197(74 \%)$ cases. The weekly distribution of individual cases reported by date of onset of symptoms peaked in week 25 (mid-end June) with 1,684 cases reported in week 25 and 1,549 in week 26 . The decreasing numbers observed after week 26 and until September 2009 can be explained by the fact that the UK, followed by other countries stopped reporting individual cases to ECDC (Figure 3).

\section{Travel-associated cases}

Of 10,643 cases with travel-related information i.e. having been outside the country of notification during the incubation period, 7,101 (67\%) were reported as domestic cases i.e. having acquired the infection in the country where they were reported. Data on travel history and week of onset of symptoms were available for 7,974 cases $(75 \%$ of cases with travel-related information) and among those, 3,333 had travelled abroad. The proportion of travel-associated pandemic influenza cases was $100 \%$ in week 16 and decreased progressively to $19 \%$ in week 25 , when the total number of reported cases was highest. In week 25, a large proportion of cases were reported as community-acquired by the UK. The proportion of travel-associated cases increased again after week 25 and remained above $50 \%$ until week 37. Large proportions had travelled to North America ( 1,314 cases, $39 \%)$ or within EU/EEA countries $(1,528$ cases, $46 \%)$. At the start of the pandemic, during weeks 16 to 23 , almost all travel-associated cases $(\geq 92 \%)$ were linked to travel to North America, and this was gradually replaced by travel within EU/EEA countries after week 24 and, from week 31 to week 38 , almost all travel-associated cases were reported within EU/EEA countries ( $\geq 83 \%)$. The percentage of cases who had travelled to other continents was $6 \%$ or less: 159 of 3,333 cases $(5 \%)$ returned from Asia, $130(4 \%)$ returned from South America and 99 (3\%) returned from another country, mainly Australia.

\section{Hospitalised cases}

The median of the weekly percentage of hospitalised cases by country was $21 \%$ with an IQR of 13 to $29 \%$ and a 95th percentile of $40 \%$ in 25 EU/EEA countries. Information on hospitalisation was not reported by Iceland, Spain and Slovenia (Table 1). Seven countries were identified with a median proportion of hospitalised cases greater than $40 \%$ (95th percentile): Austria, Bulgaria, France, Latvia, Poland, Portugal and Romania. These countries had similarly high hospitalisation rates during their containment phase of the pandemic which decreased when hospitalisation was no longer recommended for isolation purposes in these countries.

Age, sex and antiviral treatment

In 28 EU/EEA countries, children and young adults less than 30 years of age represented $78 \%(n=10,846)$ of cases reported and the highest age-specific 
notification rate was observed in the age group 10 to 14 years with 7.7 per 100,000 population (Figure 4). Two peaks were observed in those under 30 years of age: the first peak, in 10 to 14 year-olds, corresponded to a series of school outbreaks reported for example in the UK and Germany $[7,8]$. The second peak was

\section{FIGURE 3}

Total $(\mathrm{n}=7,974)$, domestic $(\mathrm{n}=4,641)$ and travel-associated $(3,333)$ cases of 2009 pandemic influenza $\mathrm{A}(\mathrm{H} 1 \mathrm{N1})$ virus infection in European Union and European Economic Area countries by week of onset and continent of travel, 19 April (week 16) 20 September (week 38) 2009

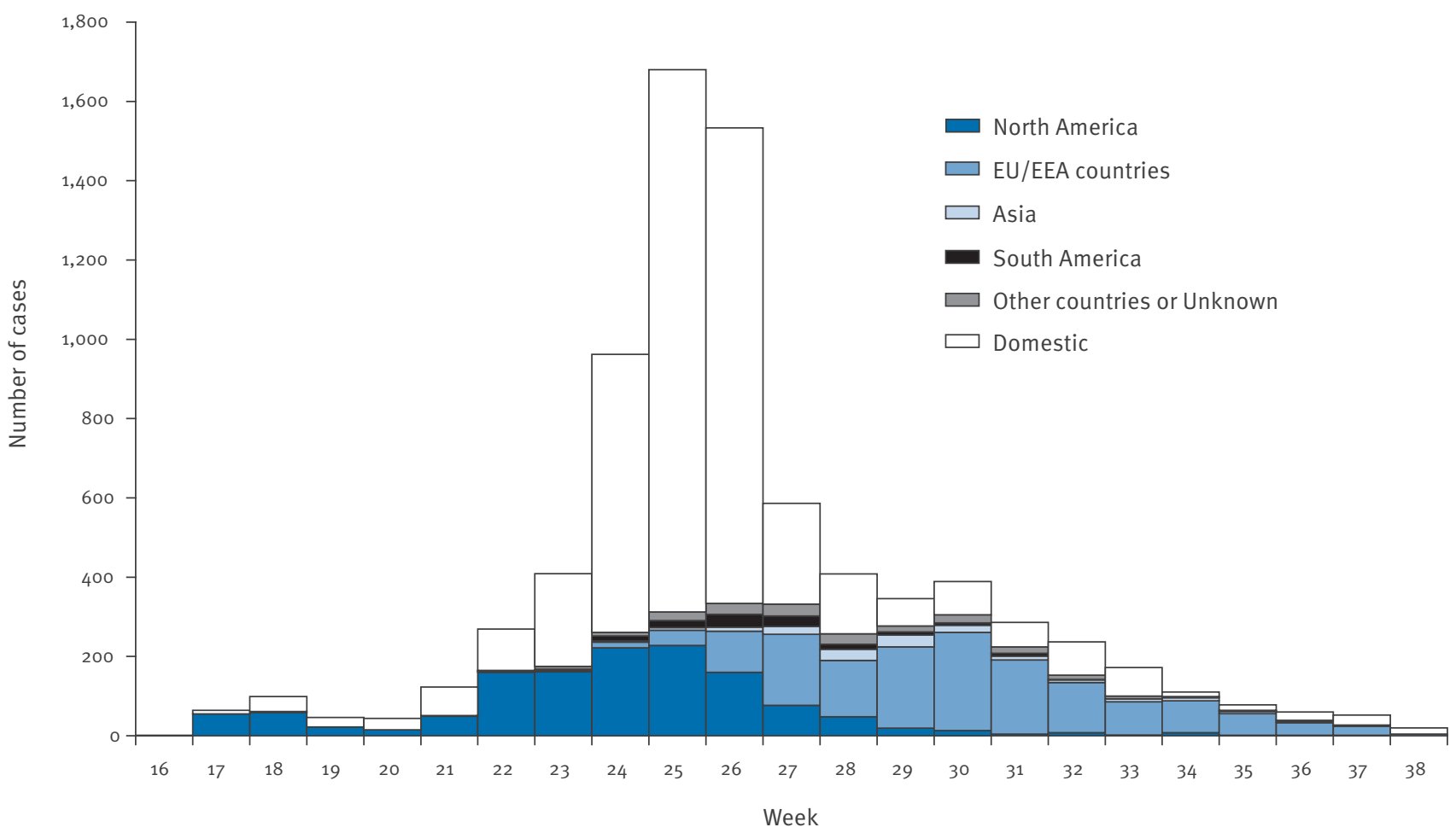

EEA: European Economic Area ; EU: European Union.

\section{FIGURE 4}

Age-specific notification rate of 2009 pandemic influenza A(H1N1) cases reported by 28 European Union and European Economic Area countries, individual case reports, 5 May - 22 September 2009, $(n=10,846)$

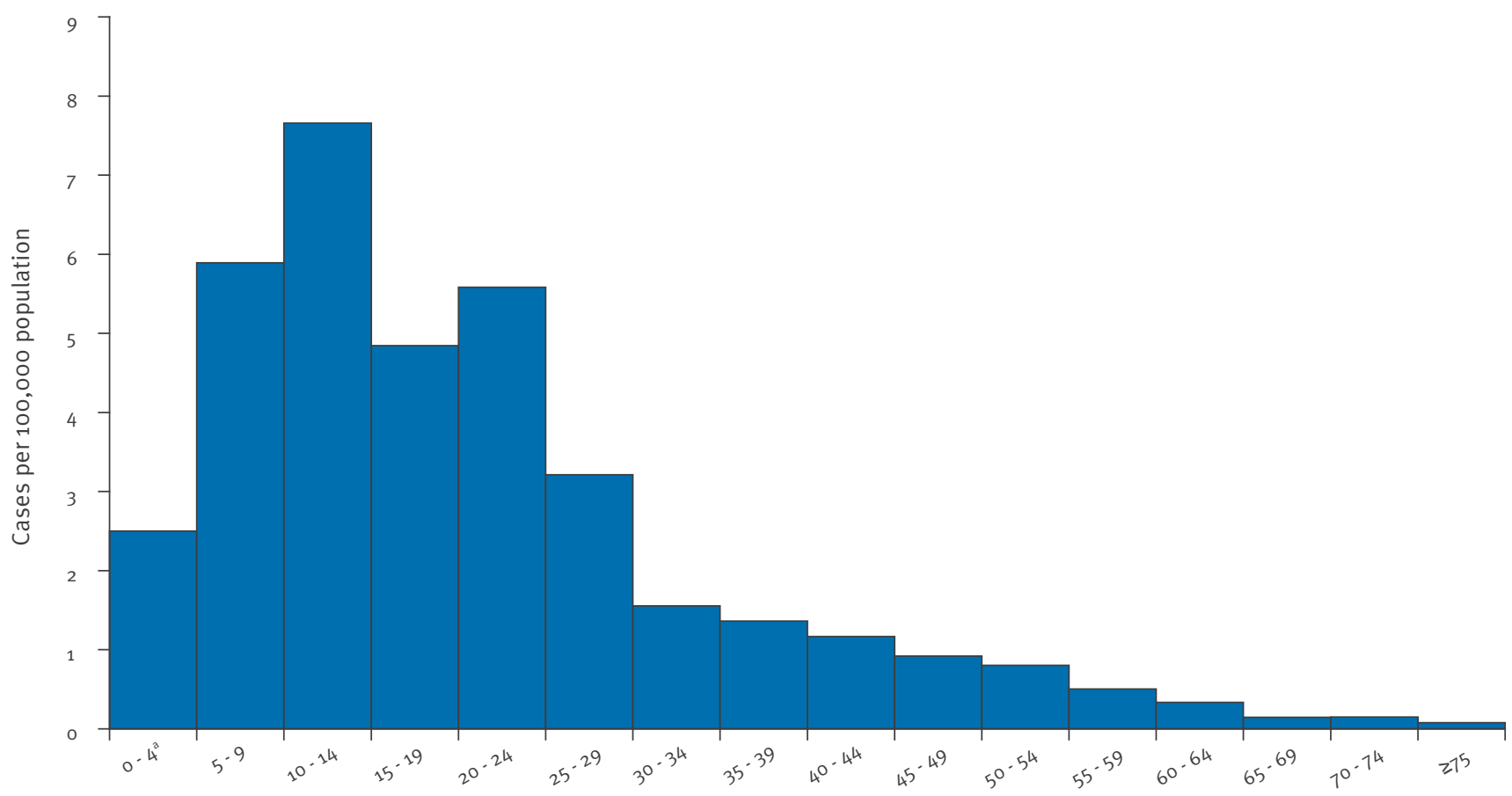

Age group 
attributed to a higher number of travel-associated cases in 20 to 24 year-olds. A decreasing trend over time in the notification rate was observed in individuals aged over 29 years (Figure 4). Five age groups were

\section{TABLE 2}

Characteristics of 2009 pandemic influenza A(H1N1) cases reported in 28 European Union and European Economic Area countries ( $n=11,037$, except for underlying conditions, $n=5,205), 5$ May - 22 September 2009

\begin{tabular}{|c|c|c|c|c|c|c|c|c|c|}
\hline \multirow{2}{*}{ Variables } & \multirow{2}{*}{ Category } & \multirow{2}{*}{ Number of cases (\%) } & \multirow{2}{*}{ Completeness \% } & \multicolumn{6}{|c|}{ Age } \\
\hline & & & & Median age & $\% 0-9$ & $\% 10-19$ & $\% 20-29$ & $\% 30-59$ & $\% \geq 60$ \\
\hline Sex & M & $5,224(53)$ & 89 & 19 & 19 & 32 & 28 & 20 & 2 \\
\hline \multirow[t]{2}{*}{ Travel-associated } & $\mathrm{Y}$ & $3,542(33)$ & 96 & 24 & 8 & 22 & 39 & 28 & 2 \\
\hline & $\mathrm{N}$ & 7,101 & & 14 & 26 & 37 & 20 & 16 & 1 \\
\hline \multirow[t]{3}{*}{ Treatment } & Antiviral & $2,440(26)$ & 85 & 22 & 12 & 28 & 33 & 25 & 2 \\
\hline & Other & 2,759 (29) & & 15 & 25 & 34 & 22 & 17 & 1 \\
\hline & $\mathrm{N}$ & $4,193(45)$ & & 16 & 24 & 33 & 23 & 18 & 1 \\
\hline Prophylaxis & & $110(4)$ & 28 & 21 & 17 & 26 & 26 & 28 & 3 \\
\hline $\begin{array}{l}\text { Vaccination against } \\
\text { seasonal influenza }\end{array}$ & & $263(3)$ & 81 & 28 & 9 & 17 & 25 & 36 & 12 \\
\hline Complication & & $94(3)$ & 26 & 26 & 10 & 19 & 28 & 37 & 6 \\
\hline
\end{tabular}

F: female; M: male; N: no; Y: yes

a It was not possible to calculate the proportion of completeness for underlying condition as the category 'none' did not exist for this variable.

\section{FIGURE 5}

Underlying conditions of 2009 pandemic influenza A(H1N1) cases reported in 26 European Union and European Economic Area countries, 5 May - 22 September 2009 ( $\mathrm{n}=331)$

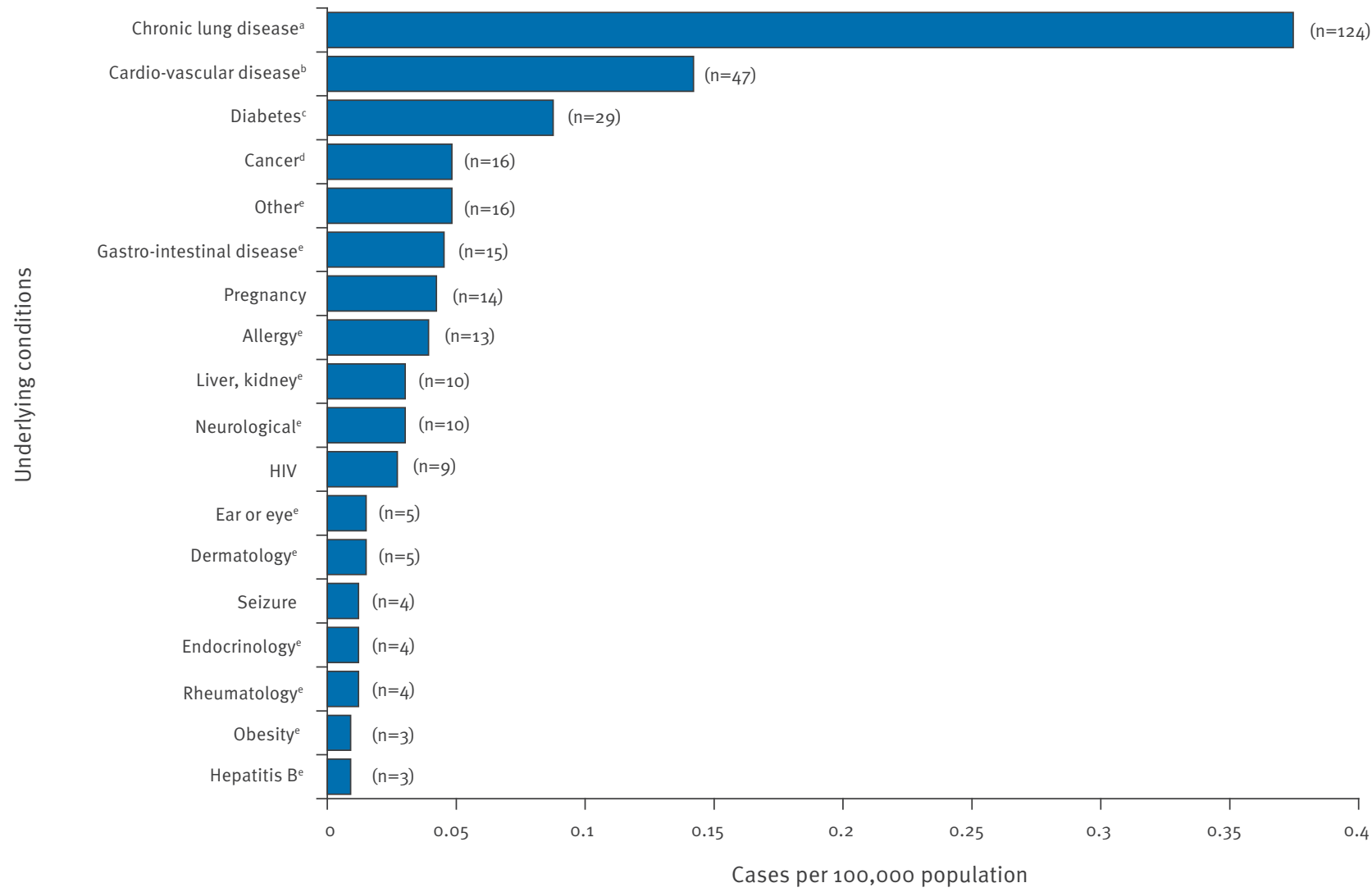

HIV: Human immunodeficience virus.

a Include 33 cases reported with asthma as a text field.

${ }^{b}$ Include cases reported with other conditions: hypertension, lung disease, kidney disorder, obesity.

' Include cases reported with other conditions: hypertension, asthma, obesity.

d Include cases reported with other conditions: seizure and/or diabetes and/or other condition.

e Reported as text field. 
further analysed: 0 to 9 years ( $20 \%$ of all cases), 10 to19 years (32\%), 20 to 29 years ( $26 \%), 30$ to 59 years (20\%), and over 60 years ( $2 \%)$.

Table 2 describes the pandemic influenza cases, completeness of reporting, median age and distribution by age group for the variables defined above. Completeness of reporting was over $80 \%$ for all variables except antiviral prophylaxis (28\%) and complication (26\%).

The male-to-female ratio was $1.1(n=9,872$ cases with available information). The median age of pandemic influenza cases was significantly higher among those who had travelled abroad (24 years) than among domestic cases (14 years), ( $z=-31.4, p<0.001)$. Fortyfive per cent $(n=9,392)$ of cases did not receive any antiviral treatment, $26 \%(2,415)$ received oseltamivir, $0.3 \%$ (25) zanamivir and $29 \%(2,759)$ another treatment which was specified in 104 (4\%) persons only, 66 of those had received antibiotics. As expected, the proportion of patients who received oseltamivir was significantly higher among hospitalised cases (74\%) compared with non-hospitalised cases (18\%). Prophylaxis was administered to 4\% (110 of 3139 cases) and previous vaccination for seasonal influenza was reported for $3 \%$ (264 of 8,913 cases). Seventytwo of 262 cases ( $28 \%$ ) with available information on vaccination and underlying condition had at least one underlying condition. Complication(s) were reported in $3 \%$ (94 of 2,878 cases with available information). Sixty persons (2\%) were reported with pneumonia, 25 (0.8\%) with other respiratory infections, and six with non-specified complications.

\section{Symptoms and underlying conditions}

Frequencies of symptoms were calculated based on 4,452 cases, after exclusion of 753 (14\%) cases reported without any symptom. Fever was reported in $87 \%$, respiratory symptoms were reported in $85 \%$, gastro-intestinal symptoms in $18 \%$, and for $27 \%$ of cases other symptoms, mainly fatigue or asthenia, chill, loss of appetite were noted. The proportion of gastro-enteritis was $26 \%$ among children aged less than 10 years.

Three hundred and forty-three of 5,205 (7\%) pandemic influenza cases were reported with at least one underlying condition. Underlying conditions were specified in 331 (96\%) of them. They were described as free text for 137 (41\%) cases. The most common underlying conditions were unspecified chronic lung diseases, including asthma (124 cases, 37\%). Other underlying conditions reported and associated or not with other conditions, were cardiovascular-diseases, diabetes, gastro-intestinal diseases, allergy, liver or kidney related conditions, neurological disorders, cancer, HIV. Pregnancy was reported in 14 women (4\%) (Figure 5).

\section{Epidemiological characteristics and outcomes}

For analyses of associations between hospitalisation and potential risk factors the age group 10 to 19 years was chosen as reference group as it had the highest age-specific notification rate. Univariate analysis shows that factors associated with hospitalisation are underlying condition (Odds ratio (OR) 1.95, 95\% confidence interval $(\mathrm{Cl})$ 1.00-2.73), seasonal influenza vaccination (OR 1.59, 95\% Cl 1.04-2.41), and age group 20 to 29 years (OR 1.32, $95 \% \mathrm{Cl} 1.00-1.74)$. In the multivariate model only underlying condition remained associated with hospitalisation (OR 1.61, 95\% Cl 1.07-2.43). Analysis of associations between complications and potential risk factors for complications were performed on data reported by 25 countries $(n=2,878$, no data reported on complication by Belgium, Slovenia and Spain). Univariate analysis shows that factors associated with complication were: age groups 30 to 59 years (OR 2.1, 95\% Cl 1.22-3.88) and over 60 years (OR $4.13,95 \% \mathrm{Cl} 1.58-10.8)$ and underlying condition (OR $3.65,95 \% \mathrm{Cl} 2.24-5.95)$. In the multivariate model only underlying condition remained associated with complication (OR 3.18, 95\% 1.91-5.27).

\section{Discussion}

The pandemic influenza cases reported in this article characterise the first wave of the 2009 pandemic in EU/EEA countries. They include a large proportion of travel-related cases that are not necessarily representative of the population affected by the pandemic during the following winter wave. Also representativeness of data varied between countries. The weekly notification rate calculated for aggregated data is a proxy for the notification rate of pandemic influenza over the summer months of 2009. Two peaks were observed: one in week 26 and one in week 31. The first is probably due to a reporting artefact in week 26 , when a large number of cases from previous weeks were reported by the UK. The second peak marks the maximum number of cases reported during the first pandemic wave in EU/ EEA countries. The sentinel surveillance of influenzalike illness (ILI) and acute respiratory infections (ARI) also showed two peaks at a time similar to that of the reporting data: one in week 25 and one in week 31 [18].

High notification rates in specific countries like Cyprus and Malta can probably be explained by an increase of their population during the summer holiday season that could not be taken into account in the denominator.

The reported percentage of hospitalised patients in $(21 \%)$ seems extremely high. At the beginning of the pandemic, hospitalisation was used for isolation purposes in some countries and this may have inflated the percentage rather than a high number of severe cases. In the Netherlands, a country that did not recommend hospitalisation for isolation purposes, a hospitalisation rate of only $2.2 \%$ (35 of 1,622 patients with confirmed pandemic influenza) was reported until 14 August 2009, when a change in notification criteria to only hospitalised patients was implemented [19].

Case-based data was available for merely $21 \%$ of the reported aggregated cases. However, this was expected because the purpose of the case-based system was to 
capture the first few hundred cases of pandemic influenza reported in all Member States, while case-based reporting was still feasible. This purpose was achieved in most countries that have reported more than 100 cases in the aggregated reports.

\section{TABLE 3}

Univariate and multivariate analysis for factors influencing hospitalisation and complications of 2009 pandemic influenza A(H1N1) cases in 18 European Union and European Economic Area countries, 5 May - 22 September 2009

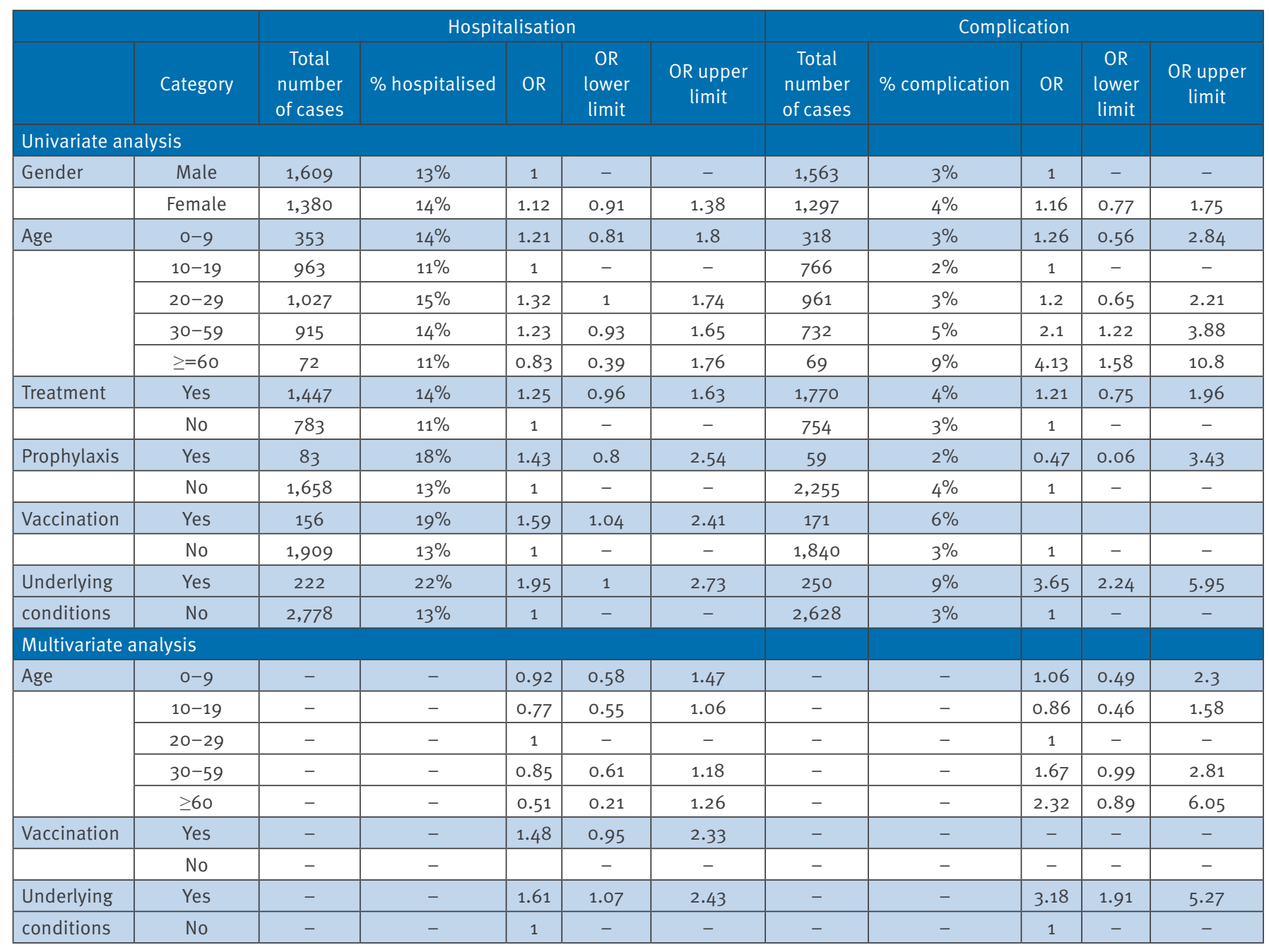

OR: Odds ratio.

\section{TABLE 4}

Percentage of underlying and co-morbid conditions reported in studies performed among patients hospitalised with 2009 pandemic influenza $\mathrm{A}(\mathrm{H} 1 \mathrm{~N} 1)$

\begin{tabular}{|c|c|c|c|c|c|c|}
\hline Study & Number of patients & Chronic lung disease, including asthma & Cardio-vascular disease & Diabetes & Obesity & Pregnancy \\
\hline US [11] & 272 & $36 \%$ & $13 \%$ & $15 \%$ & - & $7 \%$ \\
\hline $\begin{array}{l}\text { US, California } \\
\text { [12] }\end{array}$ & 1,088 & $37 \%$ & $15 \%$ & $11 \%$ & $48 \%$ & $10 \%$ \\
\hline Canada $^{\mathrm{a}}[13]$ & 168 & $32 \%^{\mathrm{b}}$ & $15 \%$ & $21 \%$ & $33 \%$ & $8 \%$ \\
\hline $\begin{array}{l}\text { Australia \& New } \\
\text { Zealand }{ }^{a}[14]\end{array}$ & 722 & $33 \%$ & $11 \%^{c}$ & $16 \%$ & $29 \%$ & $9 \%$ \\
\hline Mexico $^{\mathrm{a}}[15]$ & 58 & $7 \%$ & $10 \%{ }^{d}$ & $17 \%$ & $36 \%$ & n.a. \\
\hline EU/EEA & 331 & $37 \%$ & $15 \%$ & $9 \%$ & & $4 \%$ \\
\hline
\end{tabular}

EEA: European Economic Area; EU: European Union; US: United States.

a Patients hospitalised in critical care units.

${ }^{\mathrm{b}}$ Asthma and/or chronic obstructive pulmonary disease.

' Only chronic heart failure.

${ }^{d}$ Arrhythmia and valvular heart diseases. 
The completeness of data for prophylaxis (28\%) and complication (26\%) was low. This can be interpreted in two different ways: either the missing information corresponds to 'no prophylaxis' or 'no complication', or to unknown information. As we chose to remove missing values from the denominator, proportions of persons who have received prophylaxis or with complication(s) may be over-estimated in our analysis.

Clinical presentations of patients reported in our system are similar to those listed in a review (WHO consultation) of clinical aspects of 2009 pandemic influenza [20]. In September 2009, the number of cases reported without any symptom was considered as quite high $(14 \%)$ as information about the proportion of asymptomatic cases was still scares at that time. Asymptomatic cases when reported in the context of tracing contacts during the containment phase could have been underestimated if contact tracing was not systematically performed.

However, it is not known if these cases were really asymptomatic or if symptoms were not reported. In the latter case, $14 \%$ would be an over-estimation of the proportion of asymptomatic cases. Serological surveys are the only way to estimate the proportion of asymptomatic 2009 pandemic influenza cases. In the meanwhile, results from such studies suggest that a considerable number of those infected with pandemic influenza $\mathrm{A}\left(\mathrm{H}_{1} \mathrm{~N}_{1}\right)$ virus may have been asymptomatic [21,22].

The overall proportion of underlying conditions ( $7 \%$ ) reported in our dataset is similar to the information reported by WHO for Ontario, Canada in June 2009 [23]. We compared proportions of underlying conditions with results from other studies among hospitalised patients with pandemic influenza in the United States [24,25], Canada [26], New Zealand [27] and Mexico [28] (Table 4). Although not necessarily all cases reported with underlying conditions in our dataset were hospitalised, the proportion of chronic lung diseases (including asthma) and cardio-vascular diseases among hospitalised patients were similar to those reported elsewhere [24-27]. However, the proportions of cases reported with metabolic conditions (diabetes and obesity) and pregnancy are lower in EU/EEA countries than those reported in hospitalised patients in the countries mentioned above. In our dataset, patients with underlying conditions were more likely to be hospitalised and underlying conditions were associated with complications regardless of age.

The fact that $45 \%$ of our cases did not receive any treatment may either indicate that they did not have a severe condition or it may reflect the treatment policies in the countries who may have only recommended treatment for severely ill.

Most cases were found in younger or middle-aged age groups. Above the age of 60 , there was a steep decline in the number of pandemic influenza $A\left(\mathrm{H}_{1} \mathrm{~N}_{1}\right)$ cases.
This could be related to previous exposure of individuals over 60 years to influenza $A\left(\mathrm{H}_{1} \mathrm{~N}_{1}\right)$ viral strains circulating after the 1918 pandemic until the 1950s [29]. Recent sero-surveys conducted in the UK [30] and in Finland [31] support this hypothesis.

Only three deaths were reported in the individual case data, this contrasts with the 159 deaths reported in EU/EEA countries in the ECDC situation report of 22 September 2009 [3]. Information about deaths is essential to assess severity of the disease appropriately. Additional monitoring systems are needed to collect this type of information in a timely manner.

\section{Conclusion}

The primary focus of this article was to present the case-based data collected during the first phase of the pandemic in EU/EEA countries and their implications for rapid public health action. The case-based reporting system was stopped in September 2010, due to the associated heavy work load and the high numbers of affected people. Case-based data were not collected in the population-based system during the second phase of the pandemic and thus our data cannot be used for comparison between the two waves. Overall, our results are in line with other observations that the early phase of the pandemic mainly affected children and young adults in European countries [7-15]. Individuals infected with 2009 pandemic influenza $A\left(\mathrm{H}_{1} \mathrm{~N}_{1}\right)$ and with underlying condition(s) were more likely to be hospitalised or to develop (severe) complications regardless of their age, particularly those with underlying respiratory diseases. The epidemiological information collected during the first wave of the pandemic provided some initial indication to determine risk groups and vaccination strategies. In the early phase of the pandemic, results from serological studies would have been helpful to determine if and to what extent individuals over 60 years have pre-existing immunity against pandemic 2009 pandemic influenza $\mathrm{A}\left(\mathrm{H}_{1} \mathrm{~N}_{1}\right)$ from $\mathrm{H}_{1} \mathrm{~N}_{1}$ strains circulating after the 1918 pandemic up until the 1950s. Our reporting system provided baseline data and helped to guide initial public health recommendations, however, as the profile of the affected population may have changed over time it is important to continue monitoring. The initial surveillance system was followed by a case-based reporting system of severe acute respiratory infections among influenza cases. Both systems provided timely information of public health relevance about profiles of populations affected by 2009 pandemic influenza.

\section{Acknowledgements}

We would like to thank Johan Giesecke, Gilles Desve, Vincente Lopez and Bartoz Pedzinski for their support and contributions. 
The ECDC working group on influenza surveillance

Bruno Ciancio, Flaviu Plata, Vladimir Prikazsky, Rene Snacken, Thomas Mollet, Denis Coulombier, Angus Nicoll, Andrew Amato-Gauci.

\section{National coordinators for influenza surveillance}

Gabriela El Belazi, Hubert Hrabcik, Peter Lachner, Reinhild Strauss, Robert Muchl, Theresia Popow - Kraupp, Françoise Wuillaume, Leen Meulenbergs, Sophie Quoilin, Mira Kojouharova, Rositsa Kotseva, Teodora Georgieva, Avraam Elia, Chryso Gregoriadou, Chrystalla Hadjianastassiou, Despo Pieridou Bagatzouni, Olga Kalakouta, Jan Kyncl, Jitka Castkova, Martina Havlickova, Andreas Gilsdorf, Brunhilde Schweiger, Gabriele Poggensee, Gerard Krause, Silke Buda, Tim Eckmanns, Anne Mazick, Annette Hartvig Christiansen, Kåre Mølbak, Lars Nielsen, Steffen Glismann, Inna Sarv, Irina Dontsenko, Jelena Hololejenko, Natalia Kerbo, Olga Sadikova, Tiiu Aro, Amparo Larrauri, Pedro Arias, Pilar Perez-Brena, Inmaculada Casas and Francisco Pozo, Markku Kuusi, Petri Ruutu, Thedi Ziegler, Sophie Vaux, Isabelle Bonmarin, Daniel Lévy-Bruhl, Bruno Lina, Martine Valette, Sylvie Van Der Werf, Vincent Enouf, Ian Fisher, John Watson, Joy Kean, Maria Zambon, Richard Pebody, Mike Catchpole, Colin Campbell, Jane Jones Joanna Ellis, Jim McMenamin, Louise Shaw, Peter Coyle, William F Carman, Stefanos Bonovas, Takis Panagiotopoulos, Sotirios Tsiodras Ágnes Csohán, Istvan Jankovics, Katalin Kaszas, Márta Melles, Monika Rozsa, Zsuzsanna Molnár, Darina O'flanagan, Derval Igoe, Joan O’Donnell, Margaret Fitzgerald, Sarah Jackson, Lisa Domegan, Gillian Cullen and Aidan O Hora Suzie Coughlan, Arthur Löve, Gudrun Sigmundsdottir Isabella Donatelli, Maria Grazia Pompa, Stefania D’amato, Stefania Iannazzo, Sabine Erne, Algirdas Griskevicius, Nerija Kupreviciene, Rasa Liausediene, Danielle Hansen - Koenig, Joel Mossong, Mathias Opp, Jacques Kremer, Pierre Weicherding, Antra Bormane, Irina Lucenko, Natalija Zamjatina, Raina Nikiforova, Charmaine Gauci, Christopher Barbara, Gianfranco Spiteri, Tanya Melillo, Christophe Barbara, Daniel Cauchi,, Adam Meijer, Frederika Dijkstra, Ge Donker, Guus Rimmelzwaan, Paul Bijkerk, Tessa van 't Klooster, Lieke Wielders, Wim van der Hoek, Katerine Borgen, Susanne Dudman, Siri Helene Hauge, Olav Hungnes, Anette Kilander, Preben Aavitsland, Andrzej Zielinski, Lidia Brydak, Magdalena Romanowska, Malgorzata Sadkowska - Todys, Maria Sulik, Carlos Manuel Orta Gomes, Jose Marinho Falcao, Raquel Guiomar, Teresa Maria Alves Fernandes, Adriana Pistol, Emilia Lupulescu, Florin Popovici, Viorel Alexandrescu, Annika Linde, Asa Wiman, Helena

Dahl, Sandra Rubinova, Mia Brytting, Eva Grilc, Irena Klavs, Katarina Prosenc, Maja Socan, Hana Blaskovicova, Margareta Slacikova.

\section{References}

1. World Health Organization (WHO). International health regulations (2005) -- 2nd ed. II. Title: IHR (2005). Geneva: WHO; 2008. Available from: http://whqlibdoc.who.int/ publications/2008/9789241580410_eng.pdf

2. The Early Warning and Response System for communicable diseases in the EU: an overview from 1999 to 2005. Euro Surveill. 2006;11(12):pii=666. Available from: http://www. eurosurveillance.org/ViewArticle.aspx?Articleld =666

3. European Centre for Disease Prevention and Control (ECDC). Stockholm: ECDC; 2009-2010. Daily situation reports on influenza $A\left(\mathrm{H}_{1} \mathrm{~N}_{1}\right)$. http://www.ecdc.europa.eu/en/ healthtopics/Pages/Influenza_A( $\left.\mathrm{H}_{1} \mathrm{~N}_{1}\right)$ Outbreak.aspx

4. European Commission. Commission Decision of 30 April 2009 amending Decision 2002/253/EC laying down case definitions for reporting communicable diseases to the Community network under Decision No 2119/98/EC of the European Parliament and of the Council. OJ L 110/58 1.5.2009. Available from: http://eurlex.europa.eu/LexUriServ/LexUriServ.do?uri=0 J:L:2009:110:0058:0059:EN:PDF

5. European Centre for Disease Prevention and Control (ECDC) Stockholm: ECDC; 2009-2010. Analysis of influenza $A\left(\mathrm{H}_{1} \mathrm{~N}_{1}\right)$ $v$ individual case reports in EU and EEA countries. Available from: www.ecdc.europa.eu/en/healthtopics/H1 N1/whats_new/ Pages/weekly_surveillance_reports.aspx

6. ECDC working group on influenza $A\left(\mathrm{H}_{1} \mathrm{~N}_{1}\right) v$. Preliminary analysis of influenza $A\left(\mathrm{H}_{1} \mathrm{~N}_{1}\right) v$ individual and aggregated case reports from EU and EFTA countries. Euro Surveill. 2009;14(23):pii=19238. Stockholm: ECDC; 2009. Available from: http://www.eurosurveillance.org/ViewArticle. aspx?Articleld $=19238$

7. Health Protection Agency, Health Protection Scotland, National Public Health Service for Wales, HPA Northern Ireland Swine influenza investigation teams. Epidemiology of new influenza A ( $\left.\mathrm{H}_{1} \mathrm{~N}_{1}\right)$ virus infection, United Kingdom, April - June 2009. Euro Surveill. 2009;14(22):pii=19232. Available from: www. eurosurveillance.org/ViewArticle.aspx?Articleld=19232
8. Novel influenza $A\left(\mathrm{H}_{1} \mathrm{~N}_{1}\right)$ investigation team. Description of the early stage of pandemic (H1N1) 2009 in Germany, 27 April-16 June 2009. Euro Surveill. 2009;14(31):pii=19295. Available from: www.eurosurveillance.org/ViewArticle. aspx?Articleld $=19295$

9. Surveillance Group for New Influenza $A\left(\mathrm{H}_{1} \mathrm{~N}_{1}\right)$ Virus Investigation and Control in Spain. New influenza $A\left(H_{1} N_{1}\right)$ virus infections in Spain, April-May 2009. Euro Surveill. 2009;14(19):pii=19209. Available from: www.eurosurveillance. org/ViewArticle.aspx?Articleld=19209

10. Influenza $A\left(\mathrm{H}_{1} \mathrm{~N}_{1}\right) v$ investigation teams. Modified surveillance of influenza $A\left(\mathrm{H}_{1} \mathrm{~N}_{1}\right) v$ virus infections in France. Euro Surveill. 2009;14(29): pii=19276. Available from: www.eurosurveillance. org/ViewArticle. aspx?Articleld $=19276$

11. Surveillance Group for New Influenza $A\left(\mathrm{H}_{1} \mathrm{~N}_{1}\right)$ Virus Investigation in Italy. Virological surveillance of human cases of influenza $A\left(\mathrm{H}_{1} \mathrm{~N}_{1}\right)$ v virus in Italy: preliminary results. Euro Surveill. 2009;14(24):pii=19247. Available from: http://www. eurosurveillance.org/ViewArticle.aspx?Articleld=19247

12. Belgian working group on influenza $A\left(\mathrm{H}_{1} \mathrm{~N}_{1}\right) v$. Influenza $A\left(H_{1} N_{1}\right) v$ virus infections in Belgium, May-June 2009. Euro Surveill. 2009;14(28):pii=19270. Available from: www. eurosurveillance.org/ViewArticle.aspx?Articleld=19270

13. Hahné S, Donker T, Meijer A, Timen A, van Steenbergen J, Osterhaus A, et al. Epidemiology and control of influenza $A\left(H_{1} N_{1}\right) v$ in the Netherlands: the first 115 cases. Euro Surveill. 2009;14(27):pii=19267. Available from: http://www. eurosurveillance.org/ViewArticle.aspx?Articleld=19267

14. Lytras T, Theocharopoulos G, Tsiodras S, Mentis A, Panagiotopoulos T, Bonovas S, et al. Enhanced surveillance of influenza $\mathrm{A}\left(\mathrm{H}_{1} \mathrm{~N}_{1}\right) \mathrm{v}$ in Greece during the containment phase. Euro Surveill. 2009;14(29):pii=19275. Available from: http:// www.eurosurveillance.org/ViewArticle.aspx?Articleld $=19275$

15. Health Protection Agency (HPA). Pandemic H1N1 2009 in England: an overview of initial epidemiological findings and implications for the second wave. Available from: http://www. hpa.org.uk/web/HPAwebFile/HPAweb_C/1258560552857

16. Eurostat. [Internet]. Total population of European Union and European Economic Area countries on 1 January. Available from: http://epp.eurostat.ec.europa.eu/tgm/table.do?tab=tabl e\&language $=$ en $\&$ pcode $=$ tpso0001\&tableSelection $=1 \&$ footnote $\mathrm{s}=$ yes\&labeling $=$ labels\&plugin $=1$

17. World Health Organization (WHO). Human infection with pandemic $\left(\mathrm{H}_{1} \mathrm{~N}_{1}\right) 2009$ virus: updated interim WHO guidance on global surveillance, 10 July 2009. Available from: http:// www.who.int/csr/disease/swineflu/guidance/surveillance/ WHO_case_definition_swine_flu_2009_04_29.pdf

18. European Centre for Disease Prevention and Control (ECDC). The $2009 \mathrm{~A}\left(\mathrm{H}_{1} \mathrm{~N}_{1}\right)$ pandemic in Europe. Stockholm: ECDC; 2010. http://ecdc.europa.eu/en/publications/Publications/101108 SPR pandemic experience.pdf

19. van 't Klooster TM, Wielders CC, Donker T, Isken L, Meijer A, van den Wijngaard CC, et al. Surveillance of Hospitalisations for 2009 Pandemic Influenza $A\left(\mathrm{H}_{1} \mathrm{~N}_{1}\right)$ in the Netherlands, 5 June - 31 December 2009. Euro Surveill. 2010;15(2):pii=19461. Available from: http://www.eurosurveillance.org/ViewArticle. aspx?Articleld $=19461$

20. Writing committee of the WHO consultation. Clinical aspects of pandemic 2009 influenza. $A\left(\mathrm{H}_{1} \mathrm{~N}_{1}\right)$ virus infection. N Engl J Med. 362(18):1708-19.

21. Aho M, Lyytikaïnen $O$, Nyholm JE, Kuitunen T, Rönkkö E, Santanen R, Ziegler T, Nikkari S. Outbreak of 2009 pandemic influenza $A\left(\mathrm{H}_{1} \mathrm{~N}_{1}\right)$ in a Finnish garrison - a serological survey. Euro Surveill. 2010;15(45):pii=19709. Available from: http:// www.eurosurveillance.org/ViewArticle.aspx?Articleld=19709

22. World health Organization (WHO). Seroepidemiological studies of pandemic influenza $A\left(\mathrm{H}_{1} \mathrm{~N}_{1}\right) 2009$ virus. Wkly Epidemiol Rec. 2010;85(24):229-35

23. World Health Organization (WHO). Epidemiology summary of pandemic influenza a(H1N1) 2009 virus - Ontario, Canada, June 2009. Weekly epidemiological record. 2009;84(47), 485-92. Available from: http://www.who.int/wer/2009/wer8447.pdf

24. Jain S, Kamimoto L, Bramley AM, Schmitz AM, Benoit SR, Louie J, et al. 2009 Pandemic Influenza A ( $\left.\mathrm{H}_{1} \mathrm{~N}_{1}\right)$ Virus Hospitalizations Investigation Team. Hospitalized patients with $2009 \mathrm{H}_{1} \mathrm{~N}_{1}$ influenza in the United States, April-June 2009. N Engl J Med. 2009;361(20):1935-44

25. Louie JK, Acosta M, Winter K, Jean C, Gavali S, Schechter R, et al. Factors associated with death or hospitalization due to pandemic 2009 influenza $\mathrm{A}\left(\mathrm{H}_{1} \mathrm{~N}_{1}\right)$ infection in California. JAMA. 2009;302(17):1896-902.

26. Kumar A, Zarychanski R, Pinto R, Cook DJ, Marshall J, Lacroix J, et al.; Canadian Critical Care Trials Group $\mathrm{H}_{1} \mathrm{~N}_{1}$ Collaborative. Critically ill patients with 2009 influenza $A\left(\mathrm{H}_{1} \mathrm{~N}_{1}\right)$ infection in Canada. JAMA. 2009 Nov 4;302(17):1872-9. Epub 2009 Oct 12 
27. ANZIC Influenza Investigators, Webb SA, Pettilä V, Seppelt I, Bellomo R, Bailey M, et al. Critical care services and 2009 $\mathrm{H}_{1} \mathrm{~N}_{1}$ influenza in Australia and New Zealand. N Engl J Med. 2009;361(20):1925-34.

28. Domínguez-Cherit G, Lapinsky SE, Macias AE, Pinto R, Espinosa-Perez $L$, de la Torre $A$, et al. Critically Ill patients with 2009 influenza $A\left(\mathrm{H}_{1} \mathrm{~N}_{1}\right)$ in Mexico. JAMA. 2009;302(17):1880-7.

29. Centers for Disese Control and Prevention (CDC). Serum crossreactive antibody response to a novel influenza $A\left(\mathrm{H}_{1} \mathrm{~N}_{1}\right)$ virus after vaccination with seasonal influenza vaccine. MMWR Morb Mortal Wkly Rep. 2009;58(19);521-4.

30. Miller E, Hoschler K, Hardelid P, Stanford E, Andrews N, Zambon M. Incidence of 2009 pandemic influenza A H1N1 infection in England: a cross-sectional serological study. Lancet. 2010;375(9720):1100-8.

31. Ikonen N, Strengell M, Kinnunen L, Österlund P, Pirhonen J, Broman $M$, et al. High frequency of cross-reacting antibodies against 2009 pandemic influenza $A\left(\mathrm{H}_{1} \mathrm{~N}_{1}\right)$ virus among the elderly in Finland. Euro Surveill. 2010;15(5): pii=19478. Available from: http://www.eurosurveillance.org/ViewArticle. aspx?Articleld $=19478$ 